\title{
Pyrolysis Mass Spectrometry of Whole Cells, Cell Walls and Isolated Cell Wall Polymers of Bacillus subtilis var. niger WM
}

\author{
By JAAP J. BOON, ${ }^{1+*}$ WILLEM R. DE BOER, ${ }^{2}$ FRED J. KRUYSSEN 2 \\ AND JAN T. M. WOUTERS ${ }^{2}$ \\ ${ }^{1}$ Netherlands Institute for Sea Research, P.O. Box 59, Texel, The Netherlands \\ ${ }^{2}$ Laboratory of Microbiology, University of Amsterdam, Nieuwe Achtergracht 127, \\ P.O. Box 20245, 1000 HE Amsterdam, The Netherlands
}

(Received 9 April 1980; revised 27 June 1980)

\begin{abstract}
Bacillus subtilis var. niger WM was grown in continuous culture under phosphate-limited and under magnesium-limited conditions. Whole cells, cell walls and the isolated wall polymers peptidoglycan, teichoic acid and teichuronic acid were analysed by Curie-point pyrolysis mass spectrometry. Characteristic ion peaks for the wall polymers were established and facilitated the interpretation of the mass pyrograms of walls and whole cells. The mass pyrograms of magnesium-limited cells showed the characteristic peaks for protein, peptidoglycan and teichoic acid. Phosphate-limited cells showed peaks characteristic of teichuronic acid instead of teichoic acid.
\end{abstract}

\section{INTRODUCTION}

Pyrolysis techniques such as pyrolysis gas chromatography and pyrolysis mass spectrometry have found wide application in such divergent fields as chemical synthesis, biochemistry, soil science, exobiology, forensic science and microbiology (for reviews, see Irwin, $1979 a, b)$. Meuzelaar and coworkers pioneered the field of pyrolysis mass spectrometry and its use for discrimination of mainly clinically important micro-organisms (Meuzelaar \& Kistemaker, 1973; Meuzelaar et al., 1975 a, b, 1977). Complete automation of sample handling and pyrolysis, associated with a dedicated microcomputer for data acquisition in a specially designed Curie-point pyrolysis mass spectrometer, guarantee the analytical reproducibility of the mass pyrograms (Meuzelaar et al., 1977; Eshuis et al., 1977).

The usefulness of pyrolysis mass spectrometry in microbial taxonomy is, to a great extent, based on the assumption that the composition of a bacterium has a given constancy. It is now well established, however, that bacterial composition is largely influenced by growth conditions (for review, see Tempest \& Neijssel, 1978). Irwin (1979b), in his review on pyrolysis of bacteria, pointed to the influence of growth parameters on cell composition and, consequently, on cell pyrograms. It was one of the aims of the present study to show the variation in the mass pyrograms of whole cells of a micro-organism caused by the growth conditions.

Recent pyrolysis mass spectrometric work has concentrated on immunogenic polysaccharides isolated from Neisseria meningitidis and Escherichia coli hospital strains (Haverkamp et al., 1980a,b). These studies demonstrated the potential of the method to relate whole cell pyrograms to those of characteristic immunogenic polysaccharides, and so indicate the presence of these polysaccharides in whole cells. Another aim of the present study was to correlate the variation in mass pyrograms of whole cells with differences in wall composition, and thus with the occurrence of different wall polymers.

$\dagger$ Guest scientist at FOM Institute for Atomic and Molecular Physics, Kruislaan 407, Amsterdam, The Netherlands. 
The organism chosen for analysis was Bacillus subtilis because its walls and wall polymers have been well characterized (Kruyssen, 1979), thus facilitating the correlation of mass pyrograms with the chemical composition of the materials analysed. Furthermore, the phenotypic variation of the organism in response to growth conditions provided walls and whole cells of specific polymer composition (de Boer et al., 1976; de Boer, 1979; Kruyssen, 1979). This micro-organism synthesizes a teichoic acid (a glycerol phosphate polymer) during growth in environments with high concentrations of phosphorus, while at low phosphorus concentrations teichuronic acid (phosphorus-free) is found in the wall. These polymers together with peptidoglycan make up more than $95 \%$ of the wall of this Gram-positive organism.

The mass pyrograms of cells and walls of Bacillus subtilis var. niger WM from phosphorus-sufficient cultures were compared with those from phosphorus-limited cultures. These mass pyrograms were also compared with those of the isolated wall polymers peptidoglycan, teichoic acid and teichuronic acid.

\section{METHODS}

Bacterial strain and culture conditions. The strain used was Bacillus subtilis var. niger WM, described previously (de Boer et al., 1976). The organism was cultured in a 11 chemostat (LH Engineering, Stoke Poges, Bucks.) with the dilution rate at $0.2 \mathrm{~h}^{-1}$, the $\mathrm{pH}$ controlled at 7.0 and the temperature regulated at $37{ }^{\circ} \mathrm{C}$. The magnesium-limited and phosphate-limited media were made up essentially as described by Evans et al. (1970), except that the overall concentration of each nutrient was three-quarters of that specified. Glucose was provided as the carbon source at a final concentration of $22.5 \mathrm{~g} \mathrm{l}^{-1}$. The cells were harvested as described by de Boer et al. (1976).

Preparation of cell walls and wall polymers. Walls of $B$. subtilis var. niger WM, either from magnesium-limited or phosphate-limited cultures, were prepared as described by de Boer et al. (1976).

Teichoic acid was extracted from walls prepared from magnesium-limited cells as described by de Boer et al. (1978). The residual wall material pelleted after teichoic acid extraction was used as the peptidoglycan preparation (purity about $90 \%$ ).

Teichuronic acid was extracted from walls of phosphate-limited cells. Any residual teichoic acid was removed by a preliminary $\mathrm{NaOH}$ extraction of the walls (de Boer et al., 1978). Teichuronic acid was solubilized by stirring the wall suspension $\left(10 \mathrm{mg} \mathrm{ml}^{-1}\right)$ in $5 \%(\mathrm{w} / \mathrm{v})$ trichloroacetic acid slowly for $16 \mathrm{~h}$ at $37^{\circ} \mathrm{C}$, according to Wright \& Heckels (1975). The wall residues were removed by centrifugation $(12000 \mathrm{~g}, 15 \mathrm{~min})$ and the supernatant was extracted five times with ether to remove the trichloroacetic acid. The extracted supernatant was brought to pH 6.5 and freeze-dried.

Sample preparation for pyrolysis. Samples of bacterial cells, walls and purified wall polymers were suspended in saline phosphate buffer ( $\mathrm{pH} \mathrm{7.2)}$ and homogenized using an ultrasonic bath. Portions of each suspension were applied to sample carriers (ferromagnetic wires); about $5 \mu \mathrm{g}$ sample was placed on each wire in this way. The solvent was removed in vacuo with continuous rotation of the sample wires. After drying, the wires were inserted in glass tubes and mounted in the sample rack of the automatic pyrolysis mass spectrometry apparatus.

Pyrolysis mass spectrometry. The pyrolysis mass spectrometer used was described by Meuzelaar et al. (1977). The pyrolysis products were generated in vacuum $\left(10^{-6} \mathrm{Torr}\right)$ by heating the ferromagnetic sample wire in a high frequency field (Curie-point pyrolysis). The Curie temperature of the sample filaments, $510^{\circ} \mathrm{C}$, was reached $0.1 \mathrm{~s}$ after the initial generation of the high frequency field. The pyrolysis products reached the ion source via a heated buffer chamber and were subsequently ionized; a low voltage $(14 \mathrm{eV})$ was used to keep further electron impact fragmentation to a minimum.

Ions were separated by a quadrupole mass filter and detected with an electron multiplier. The ion mixture was scanned for $15 \mathrm{~s}$ at a rate of 10 scans s$^{-1}$; the ion arrival pulses were amplified, discriminated, shaped and counted by specially built ion counting equipment with a band width of $200 \mathrm{MHz}$ which allowed the recording of mass peaks over a wide dynamic range. The scan data were accumulated in the memory of a dedicated minicomputer. The resulting mass pyrogram shows the molecular ion $(\mathrm{m} / \mathrm{e})$ distribution of the pyrolysis products, normalized to total ion counts. This normalization was carried out to neutralize irreproducibility as a result of small deviations in the amount of sample pyrolysed and small variations in instrument performance. All materials in this study have been analysed twice; reproducibility of the relative peak intensities was within $10 \%$. 


\section{RES ULTS}

Mass spectral fingerprints of the freeze-dried whole cells and wall preparations of $B$. subtilis var. niger WM are shown in Fig. 1. Cells grown under phosphate limitation showed a mass pyrogram (Fig. $1 a$ ) with increased intensity of the ions $m / e 30,31,32,59,72,73,83$, $85,102,109$ and 112 compared with the magnesium-limited cells (Fig. $1 b$ ) which showed increased intensities of the ions $m / e 28,56,81,110$ and 126 .

Both cell types exhibited peak series at $m / e 17,34,48,69,92,94,98,108,117$ and 131 , which disappeared or were greatly decreased in intensity in the mass pyrograms of the corresponding wall preparations of the bacteria. Ion peak $m / e 98$, tentatively identified as furfuryl alcohol, is a major peak in the mass pyrogram of DNA (Posthumus et al., 1974a) and is generated from the deoxyribose units in DNA. The other ion peaks - tentatively identified as ammonia ( $m / e$ 17), hydrogen sulphide $(\mathrm{m} / \mathrm{e} 34)$, methanethiol $(\mathrm{m} / \mathrm{e} 48)$, 2-methylpropanenitrile $(m / e$ 69), toluene $(m / e ~ 92)$, phenol $(m / e ~ 94)$, cresol $(m / e ~ 108)$,

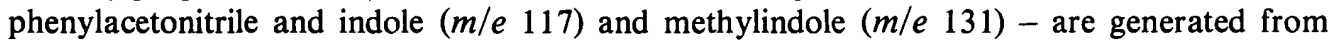
amino acids in proteins (Simmonds, 1970; Simmonds et al., 1972; Irwin, 1979 b).

Several ion peaks were more intense in the pyrograms of the walls than in those of the corresponding whole cells. The ion series $m / e 59,72,73$ and 85 was markedly increased and the series $m / e 31,32,83,95,102,112,125,137$ and 139 was moderately increased in pyrograms of walls of phosphate-limited cells (Fig. 1c). In the spectrum of walls of magnesium-limited cells the ions $m / e 28,31,32,44,55,59,60,61,72,73,110,126$ and 136 showed increased intensities (Fig. 1d). These different intensity shifts in the ion series in the spectra of both wall preparations compared with the spectra of their corresponding whole cells obviously reflect the specific wall composition in phosphate-limited and magnesiumlimited bacteria, respectively.

The wall polymers of these bacteria have been isolated and characterized by ${ }^{13} \mathrm{C}$ nuclear magnetic resonance (n.m.r.) spectroscopy and other chemical procedures (de Boer et al., 1976; de Boer, 1979; Kruyssen, 1979). The wall of phosphate-limited B. subtilis var. niger WM is composed of peptidoglycan and teichuronic acid. The walls of magnesium-limited cells contain peptidoglycan and teichoic acid. The mass pyrograms of the walls can be understood by comparison with the pyrograms of peptidoglycan, teichoic acid and teichuronic acid shown in Fig. 2.

Peptidoglycan is present in both bacterial phenotypes and makes up around $50 \%$ of the wall dry weight (Kruyssen, 1979). It is composed of linear $N$-acetylated aminosugar chains interconnected with peptide bridges. The aminosugar chains consist of alternating $(1,4)$ - $\beta$-linked $N$-acetylglucosamine and muramic acid units. The peptide bridge in $B$. subtilis var. niger WM consists of L-alanine, D-glutamic acid, meso-D,L-diaminopimelic acid and D-alanine (Kruyssen, 1979).

The mass pyrogram of peptidoglycan (Fig. $2 a$ ) showed a qualitative resemblance to the spectrum of chitin, a homopolymer of $(1,4)-\beta-N$-acetyl-D-glucosamine (Meuzelaar et al., 1974; Weyman, 1977). The two series of $N$-containing pyrolysis products, which are characteristic of aminosugars, i.e. $m / e 67,81,95,109,123,137,151$ and $m / e 69,83,97,111$, $125,139,153$, found in chitin, were also found in the pyrogram of peptidoglycan. The observed relative intensities of both ion series in the peptidoglycan spectrum differed considerably from those in the chitin spectrum, which must be related to the differences in composition. $\mathrm{N}$-Acetylation of the polymer was exemplified by $\mathrm{m} / \mathrm{e} 59$ (acetamide). The generation of $m / e 59$ as acetamide from bacterial cells has been shown by pyrolysis gas-liquid chromatography/mass spectrometry (Simmonds, 1970) and, recently, by pyrolysis mass spectrometry/collision induced dissociation mass spectrometry (Louter et al., 1980). The relative intensity of $m / e 59$ in the peptidoglycan pyrogram was high compared with that found in other $N$-acetylated aminosugar polymers (see also Meuzelaar et al., 1981). Ion peaks which are usually not encountered in any intensity in $N$-acetylated aminosugars 


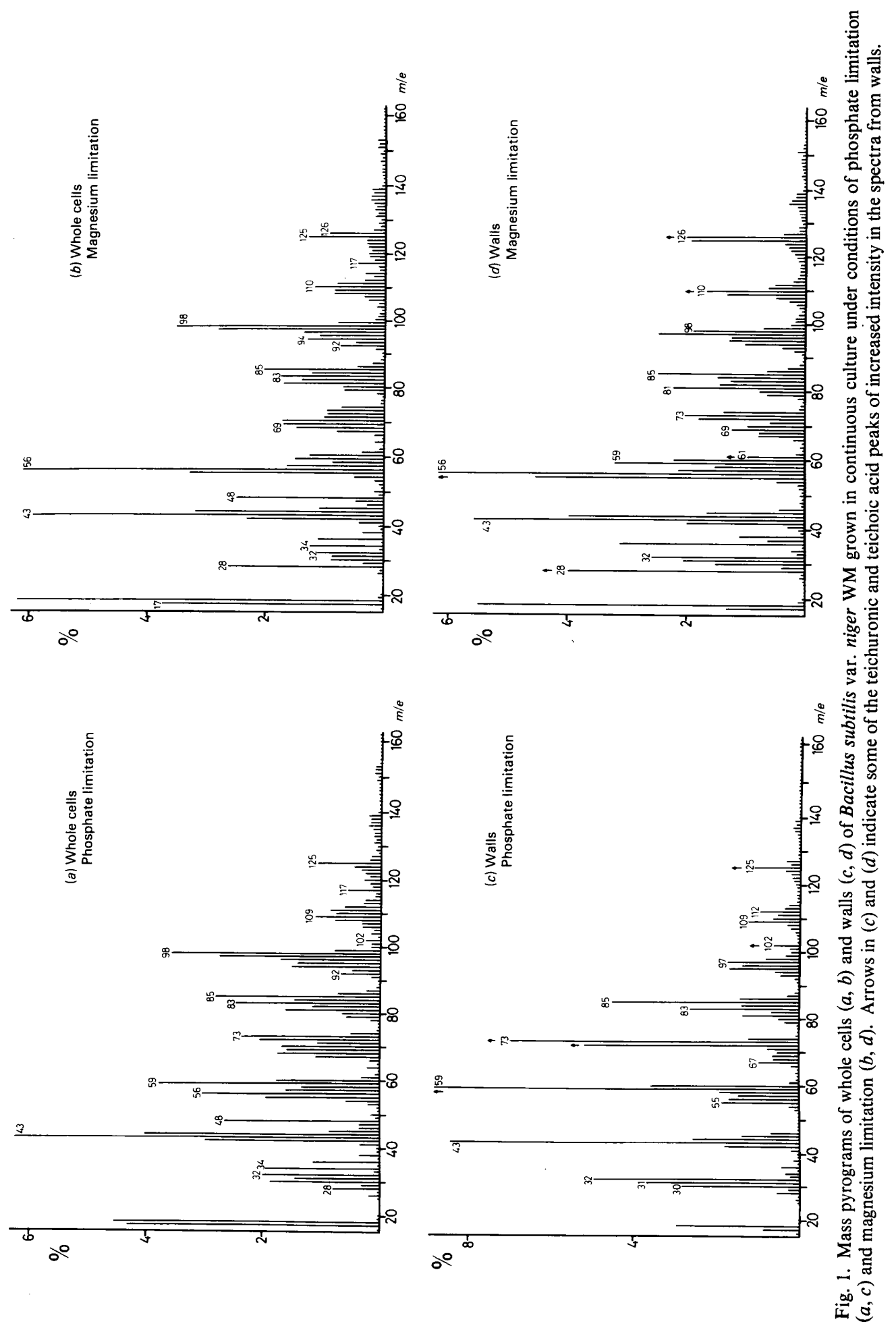



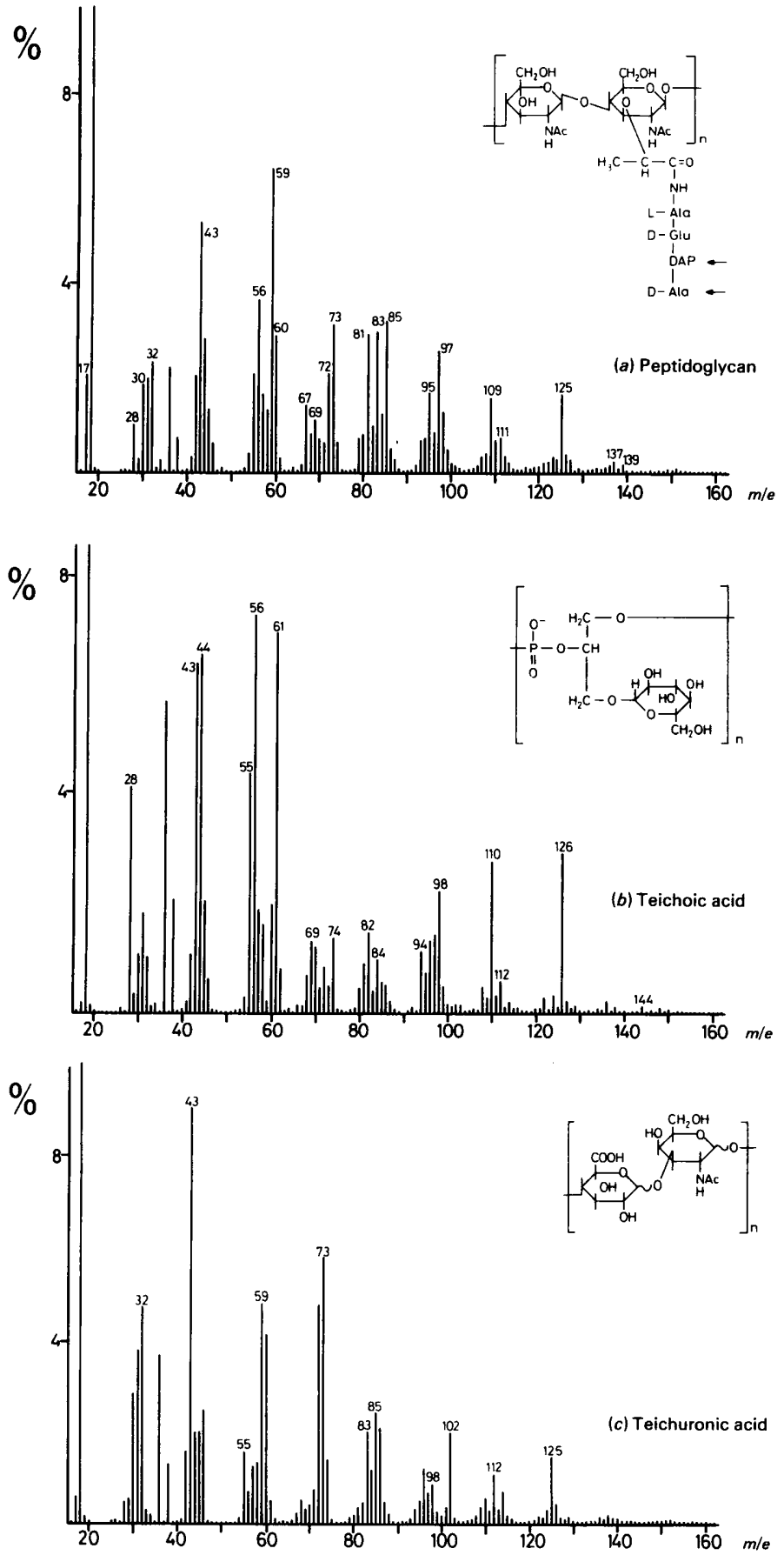

Fig. 2. Mass pyrograms of the wall polymers peptidoglycan (a), teichoic acid $(b)$ and teichuronic acid (c) isolated from Bacillus subtilis var. niger WM. 
were observed at $m / e$ 41, 55 and 56 . These ions can be interpreted as deriving from the lactylpeptide bridge in peptidoglycan. The lactic ether unit of muramic acid can generate acrolein, which appears as $m / e 56$ (molecular ion peak) and $m / e 55\left(\mathrm{M}^{+}-\mathrm{H}\right)$ (Stenhagen $e t$ $a l ., 1974$ ) in the pyrogram. The ions $m / e 41$ and part of $m / e 55$ originated from the alanine in the peptide, if these mass peaks represent the molecular ions of ethane- and propanenitrile, respectively.

The structure of the teichoic acid from B. subtilis var. niger WM has been determined by ${ }^{13} \mathrm{C}$ n.m.r. spectroscopy (de Boer et al., 1976). It consists of a polymeric 2,3-glycerol phosphate diester with glucose units in the 1 position of glycerol. The molar ratio of glycerol, phosphate and glucose is $1.00: 1 \cdot 00: 0 \cdot 88$. The mass pyrogram of teichoic acid is shown in Fig. $2(b)$. A number of the mass peaks present, i.e. $m / e$ 72, 74, 82, 84, 96, 98, 110,112 and 126, were also observed in the pyrolysis mass spectrometry analysis of hexose polysaccharides, although in different relative proportions (Posthumus et al., 1974 b). Mass peak $m / e 126$ probably represents laevoglucosenon, formed by a thermally induced dehydration of the hexose units (Shafizadeh, 1975). The other ion peaks were a result of thermolytic rearrangements which led to ketones, aldehydes and furans (Heyns \& Klier, 1968; Shafizadeh \& Lai, 1972; Schulten \& Görtz, 1978). All these mass peaks were indicative of the hexose units attached to the polymer. A special feature in the teichoic acid pyrogram was the relatively intense ion peaks $m / e 28,55,56$ and 61 . The proposed identities of these peaks are, respectively, carbon monoxide, acrolein $\left(m / e \quad 56\right.$ and $m / e \quad 55$ as $\left.\mathbf{M}^{+}-\mathrm{H}\right)$ and $\left[\mathrm{CH}_{2} \mathrm{OHCH}=\mathrm{OH}\right]$, being the major fragment ion in $70 \mathrm{eV}$ mass spectra (Budzikiewicz et al., 1964 ) and also $14 \mathrm{eV}$ mass spectra (J. Haverkamp, personal communication) of glycerol, and of vicinal triols in general.

Acrolein can be easily formed by rearrangement of the glycerol in the glycerol phosphate polymer. Thermolytic formation of glycerol from this polymer seems unlikely, since this would imply the simultaneous rupture of two PO bonds and one $\mathrm{CO}$ bond. The generation of glycerol or another vicinal triol from the non-reducing hexose units attached to the polymer, which would involve the C-2, C-3 and C-4 carbon atoms in the glucose molecule, is more plausible. No signs of phosphate groups or organophosphate complexes were found in the pyrogram of teichoic acid, which is similar to results obtained with nucleic acids (Posthumus et al., 1974a) or other phosphate-containing polymers (Meuzelaar et al., 1981) and is due to their low volatility.

Teichuronic acid is incorporated as the anionic polymer when the bacteria are grown under phosphate-limiting conditions (Ellwood, 1970; Kruyssen, 1979). The teichuronic acid consists of equimolar amounts of $\mathrm{N}$-acetylgalactosamine and glucuronic acid. These residues are glycosidically linked probably through substitution at C-3 of the $N$-acetylgalactosamine and at C-4 of the glucuronic acid, as has been concluded from ${ }^{13} \mathrm{C}$ n.m.r. data (de Boer, 1979).

The mass pyrogram of teichuronic acid is shown in Fig. 2(c). The spectrum shows a number of mass peaks pointing to $N$-acetylated aminosugars. Ion peaks $m / e 59$ (acetamide) and 73 are indicative of the $\mathrm{N}$-acetylation of the polymer. A number of aminosugar peaks, i.e. $m / e 81,83,95,97,109,111,125$, have been mentioned in the discussion of peptidoglycan above. A difference in the relative distribution of the mass peaks 97, 109, 111 and 125 was apparent in the pyrograms of teichuronic acid and peptidoglycan. Mass peak $m / e 125$ was much more intense relative to $\mathrm{m} / \mathrm{e} 109$ and 97 in teichuronic acid (Fig. $2 c$ ).

The glucuronic acid moiety showed itself by the characteristic ion $m / e 102$. The pyrogram of free glucuronic acid shows $m / e 32,43,60,72,74$ and 102 as major peaks, besides smaller peaks such as $m / e 58,61,84,85,86,87,96,98,110,112,114,124$ and 126 (unpublished result; see also Meuzelaar et al., 1981). All these peaks were present in the teichuronic acid spectrum, but with different relative intensities, presumably due to the bound form of glucuronic acid in this polymer. The pyrogram of teichuronic acid closely resembled that of hyaluronic acid, a (1,3)- $\beta$-linked polymer of glucuronic acid and $N$-acetylglucosamine (J. 
Haverkamp, personal communication) especially with respect to the relative intensity distribution of $m / e$ 125, 109 and 97 (aminosugar fragments) and the mass peaks from the glucuronic acid residue.

Earlier, we pointed out the differences in mass peak distribution in pyrograms of phosphate-limited and phosphate-sufficient (magnesium-limited) bacilli. These differences must be a result of the difference in wall composition, which is known to vary with the composition of the culture medium. Knowing the pyrograms of the wall polymers, it is now possible to assess to what extent these polymer characteristics were present in the mass pyrograms of the whole cells and walls, provided that the pyrolysis process was not completely changed by the spatial organization of the polymer in the walls.

The mass pyrogram of magnesium-limited walls (Fig. $1 d$ ) shows a prominent ion series of teichoic acid, i.e. $m / e 28,55,56,98,110,126$, and a series indicative of the peptidoglycan, i.e. $m / e 59,72,73,81,95,97,109,125$. The relative intensities of these major peaks in the wall spectrum match with those in the pyrogram of the polymers. In several cases relative intensity changes in the mass peaks of the wall spectrum arose from the superposition of ion peaks with the same nominal mass generated from the component wall polymers, for example $\mathrm{m} / \mathrm{e}$ $30,31,32,69$. However, the relative change of $m / e 61$ and 83 cannot be explained in this way (compare their ratios with 56 and 85 , respectively). The change in intensity of $m / e 61$ could have been caused by chemical interactions of other wall components with the glucose group of the teichoic acid in the wall, which was not possible in the purified specimen of the polymer. The possible significance of the change in $m / e 83$ is not clear.

Mass peaks indicative of $\mathrm{N}$-acetylated aminosugars were present in the wall spectrum of phosphate-limited cells (Fig. 1 c). There were no indications of the presence of teichoic acid, but characteristic mass peaks from teichuronic acid were observed, i.e. $m / e 102,112$, and the aminosugar peaks $m / e 81,83,97,109,125$. Since both peptidoglycan and teichuronic acid yield pyrolysis products from $\mathrm{N}$-acetylated aminosugar moieties, all the relative intensities of the pyrolysis products from these polymers were different from those observed in the spectra of the purified polymers, probably as a result of additive effects. Although this explains the extreme intensities of $m / e 59,72$ and 73 , many small changes in intensity cannot be explained in this way and instead must be due to the chemical bonds between peptidoglycan and teichuronic acid in the walls (compare $m / e$ 95-98, 102, 109-114 and 125 in Figs $1 c$ and $2 c$ ).

In view of all these observations the cell walls of phosphate-limited and phosphatesufficient bacilli can be discriminated by comparing the mass peaks $m / e 28,56,61,102$ and 126 in their respective spectra. These characteristic mass peaks are also present in the mass pyrograms of the corresponding whole cells, together with ion peaks of cytoplasmic polymers like proteins and nucleic acids.

\section{DIS CUSSION}

The mass pyrograms of the wall polymers peptidoglycan, teichoic acid and teichuronic acid are very dissimilar and show many characteristic differences. The thermal fragments of these polymers can be recognized in the pyrograms of the cell walls and of whole cells. Evidently, the mechanism of thermal degradation of the individual polymers is not so radically changed by their mode of occurrence in the wall that completely new molecular species or new very dissimilar distributions of pyrolysis products arise.

Although it is possible to relate a number of pyrolysis products to the original unit components in the polymers by comparison with the mass pyrograms of standard polymer samples, the identity of many mass peaks remains obscure and deserves more detailed structural analysis by pyrolysis mass spectrometry combined with collision induced dissociation mass spectrometry (Louter et al., 1980) or pyrolysis high resolution field ionization mass spectrometry (Schulten et al., 1973; Schulten \& Görtz, 1978).

Practically all the wall pyrolysis products occur in the mass pyrograms of the corresponding whole cells, but they are, of course, mixed with the cytoplasmic pyrolysis 
products. It seems justified to state that differences in bacterial composition, as indicated by pyrolysis mass spectrometry, are more pronounced in cell walls than in whole cells.

In general, the sugar units in the polymers yield many characteristic thermal fragmentation products and determine to a large extent the fragment intensity pattern in the pyrograms. Unfortunately, no information about the presence of peptide bridges in the peptidoglycan is obtained by this technique. Analysis of the aminosugar chains after removal of the peptide bridge may reveal characteristic mass peaks for the bridge, which remain obscure now. Another approach to reveal characteristics of the peptide bridge could be the analysis of peptidoglycan with a different structure from other bacteria (Schleifer \& Kandler, 1972) or the chemical labelling of the peptide bridge or certain of its functional groups by a pyrolysis label. Similarly, teichoic acid shows a number of characteristic pyrolysis products but no direct information is obtained about the phosphate group.

The presence of characteristic fragments of the wall polymers and their occurrence in the mass pyrograms of walls and of whole cells certainly opens up the possibility of quantifying their relative amounts in unknowns by computer techniques, such as factor analysis (Windig et al., 1980). Pyrolysis mass spectrometry combined with numerical data analysis, thus becomes a relatively easy, cheap and rapid method for monitoring changes in bacterial biopolymer composition in response to growth conditions imposed on the bacteria.

Our results demonstrate that environmental effects on the chemical composition of Gram-positive bacteria can be traced by pyrolysis methods. Since environmental influences on the composition of bacteria and other micro-organisms are fairly general, studies on chemical taxonomy using pyrolytic techniques (Irwin, 1979b) should take account of the possible importance of such effects. On the other hand, a thorough knowledge of the effects of environment on the biopolymer composition of micro-organisms provides interesting clues to the nature of their micro-habitats. This is an ecological application of the method which may gain in importance, although problems are manifold.

The authors gratefully acknowledge the hospitality of Dr J. Haverkamp and the generous support of the Biomolecular Physics Group of the FOM Institute for Atomic and Molecular Physics in Amsterdam, which provided the mass spectrometric facilities. We thank Misses A. Tom and B. Brandt for expert technical assistance. One of us (J.J.B.) is supported by the Foundation for Fundamental Biological Research (B.I.O.N.), which is subsidized by the Netherlands Organization for the Advancement of Pure Research (Z.W.O.).

\section{REFERENCES}

BOER, W. R. DE (1979). Cell wall polymers of Bacillus subtilis. Structure and metabolism. Thesis, University of Amsterdam, The Netherlands.

Boer, W. R. DE, KruYsSen, F. J., Wouters, J. T. M. \& KRUK, C. (1976). The structure of teichoic acid from Bacillus subtilis var. niger WM as determined by ${ }^{13} \mathrm{C}$ nuclear-magnetic-resonance spectroscopy. European Journal of Biochemistry 62, 1-6.

Boer, W. R. DE, Wouters, J. T. M., ANderson, A. J. \& ARChibald, A. R. (1978). Further evidence for the structure of the teichoic acids from Bacillus stearothermophilus B65 and Bacillus subtilis. European Journal of Biochemistry 85, 433-436.

Budzikiewicz, H., DJerassi, C. \& Williams, D. H. (1964). Interpretation of Mass Spectra of Organic Compounds. San Francisco: Holden-Day.

EllwooD, D. C. (1970). The wall content and composition of Bacillus subtilis var. niger grown in a chemostat. Biochemical Journal 118, 367-373.

Eshuis, W., Kistemaker, P. G. \& MeuzelaAR, H. L. C. (1977). Some numerical aspects of repro- ducibility and specificity. In Analytical Pyrolysis, pp. 151-166. Edited by C. E. R. Jones \& C. A. Cramers. Amsterdam: Elsevier.

Evans, C. G. T., Herbert, D. \& Tempest, D. W. (1970). The continuous cultivation of microorganisms. 2. Construction of a chemostat. Methods in Microbiology 2, 277-327.

Haverkamp, J., MeuzelaAR, H. L. C., Beuvery, E. C., Boonekamp, P. \& Tiesjema, R. H. (1980a). Characterization of Neisseria meningitidis capsular polysaccharides containing sialic acids by pyrolysis mass spectrometry. Analytical Biochemistry 104, 407-418.

Haverkamp, J., Guinee, P. A. M., Eshuis, W. \& Boerboom, H. A. J. $(1980 \mathrm{~b})$. Pyrolysis mass spectrometry as a rapid screening method of biological materials. In Advances in Mass Spectrometry, vol. 8, pp. 12-18. Edited by N. R. Daly. London: Heyden.

HeYNS, K. \& KLIER, M. (1968). Bräunungsreaktionen und Fragmentierungen von Kohlenhydraten. IV. 
Vergleich der flüchtigen Abbauprodukte bei der Pyrolyse von mono-, oligo- und polysacchariden. Carbohydrate Research 6, 436-448.

IRWIN, W. J. (1979a). Analytical pyrolysis - an overview. Journal of Analytical and Applied Pyrolysis 1, 3-25.

IRWIN, W. J. (1979b). Analytical pyrolysis - an overview. Applications. Journal of Analytical and Applied Pyrolysis 1, 89-122.

KRUYSSEN, F. J. (1979). The cell wall of Bacillus subtilis. Regulation of synthesis of anionic polymers. Thesis, University of Amsterdam, The Netherlands.

Louter, G. J., Stalmeier, P. F. M., BOERBOOM, A. J. H., HAverkamp, J. \& Kistemaker, J. (1980). High sensitivity in CID mass spectrometry, structure analysis of pyrolysis products. Zeitschrift für Naturforschung 35C, 6-11.

MeuzelaAR, H. L. C. \& Kistemaker, P. G. (1973). A technique for fast and reproducible fingerprinting of bacteria by pyrolysis mass spectrometry. Analytical Chemistry 45, 587-590.

MeuzelaAR, H. L. C., Kistemaker, P. G. \& Posthumus, M. A. (1974). Recent advances in pyrolysis mass spectrometry of complex biological materials. Biomedical Mass Spectrometry 1, 312319.

MeuzelaAr, H. L. C., Kistemaker, P. G. \& Tom, A. (1975a). Rapid and automated identification of microorganisms by Curie-point pyrolysis techniques. I. Differentiation of bacterial strains by fully automated Curie-point pyrolysis gas-liquid chromatography. In New Approaches to the Identification of Microorganisms, pp. 165-178. Edited by C. Hedén \& T. Illéni. New York: Wiley.

MeuzelaAR, H. L. C., Kistemaker, P. G. \& Tom, A. $(1975 b)$. Rapid and automated identification of microorganisms by Curie-point pyrolysis techniques. II. Fast identification of microbiological samples by Curie-point pyrolysis mass spectrometry. In New Approaches to the Identification of Microorganisms, pp. 179-191. Edited by C. Hedén \& T. Illéni. New York: Wiley.

MeuzelaAr, H. L. C., Kistemaker, P. G., Eshuis, W. \& Boerboom, H. A. J. (1977). Automated pyrolysis mass spectrometry; application to the differentiation of microorganisms. In Advances in Mass Spectrometry, vol. 7B, pp. 1452-1456. Edited by N. R. Daly. London: Heyden.

MeuzelaAr, H. L. C., Haverkamp, J. \& Hileman, F. D. (1981). Curie-point Pyrolysis Mass Spectrometry of Recent and Fossil Biomaterials. Compendium and Atlas (in the Press). Amsterdam: Elsevier.

Posthumus, M. A., Nibbering, N. M. M., Boerboom, A. J. H. \& Schulten, H. R. (1974a). Pyrolysis mass spectrometric studies on nucleic acids. Biomedical Mass Spectrometry 1, 352-357.
Posthumus, M. A., Boerboom, A. J. H. \& MeuzelaAR, H. L. C. $(1974 b)$. Analysis of biopolymers by Curie-point pyrolysis in direct combination with low voltage electron impact ionization mass spectrometry. In Advances in Mass Spectrometry, vol. 6, pp. 397-402. Edited by A. R. West. Barking: Applied Science Publishers.

SHAFIZADEH, F. (1975). Industrial pyrolysis of cellulosic materials. In Applied Polymer Symposium no. 28, pp. 153-174. Edited by T. E. Timell. New York: Wiley.

ShafizadeH, F. \& LAI, Y. F. (1972). Thermal degradation of 1,6-anhydro- $\beta$-D-glucopyranose. Journal of Organic Chemistry 37, 278-284.

SCHLEIfER, K. H. \& Kandler, O. (1972). Peptidoglycan types of bacterial cell walls and their taxonomic implications. Bacteriological Reviews 36, 407-477.

Schulten, H. R. \& GörTZ, W. (1978). Curie-point pyrolysis and field ionization mass spectrometry of polysaccharides. Analytical Chemistry 50, 428-433.

Schulten, H. R., Beckey, H. D., MeuzelaAR, H. L. C. \& Boerboom, A. J. H. (1973). High resolution field ionization mass spectrometry of bacterial pyrolysis products. Analytical Chemistry 45, 191195.

Simmonds, P. G. (1970). Whole microorganisms studied by pyrolysis-gas chromatography-mass spectrometry: significance for extraterrestrial life detection experiments. Applied Microbiology 20, 567-572.

Simmonds, P. G., Medley, E. E., Retcliff, M. A. \& Shulman, G. P. (1972). Thermal decomposition of aliphatic monoamino monocarboxylic acids. Analytical Chemistry 44, 2060-2066.

Stenhagen, E., Abrahamsson, S. \& Mclafferty, F. W. (1974). Registry of Mass Spectral Data, vol. 1. New York: Wiley.

TEMPEST, D. W. \& NeIJSSEL, O. (1978). Eco-physical aspects of microbial growth in aerobic nutrientlimited environments. In Advances in Microbial Ecology, vol. 2, pp. 105-153. Edited by M. Alexander. New York \& London: Plenum Press.

WEYMAN, A. C. M. (1977). The application of Curie-point pyrolysis mass spectrometry in fungal taxonomy. In Analytical Pyrolysis, pp. 225-233. Edited by C. E. R. Jones \& C. A. Cramers. Amsterdam: Elsevier.

WINDIG, W., KistemakeR, P. G., HaVERKamP, J. \& MeuzelaAR, H. L. C. (1980). Factor analysis of the influence of changes in experimental conditions in pyrolysis mass spectrometry. Journal of Analytical and Applied Pyrolysis 2, 7-18.

Wright, J. \& HeCkels, J. E. (1975). The teichuronic acid of cell walls of Bacillus subtilis W23 grown in a chemostat under phosphate limitation. Biochemical Journal 147, 187-189. 